\title{
Aborto legal: uma revisão da perspectiva clínica e Jurídica no contexto da medicina
}

\author{
Legal abortion: a review of the clinical and legal in the context of medicine \\ Aborto legal: una revisión de la clínica y legal en el contexto de la medicina \\ Roberto Silva Almeida Junior ${ }^{1 *}$, Isabel Souza Lima ${ }^{1}$, Jorge Sidney Pinheiro Moraes ${ }^{1}$.
}

\section{RESUMO}

Objetivo: Diante disso, é de grande relevância que os profissionais que realizem tal procedimento tenham conhecimentos clínicos e jurídicos sobre a temática. Portanto, a presente revisão teve como objetivo, a realizar uma pesquisa analítica dos aspectos clínicos e jurídicos do aborto legal no contexto da medicina. Métodos: Trata-se de um estudo analítico, documental, do tipo revisão integrativa de literatura, a busca foi realizada nas bases de dados SCIELO, LILACS, BDENF e PUBMED. Resultados: Foram selecionados 10 estudos, que abordaram sobre as perspectivas clínicas e jurídicas do aborto legal no Brasil. Os estudos evidenciaram que essa temática ainda é cercada por estigmas, e que muitos profissionais não têm o conhecimento suficiente da legislação. Além disso, outra pauta levantada nos estudos, é que muitas mulheres que sofrem estupro e engravidam são desacreditas pelos profissionais, necessitando apresentar um documento que prove tal fato. Considerações finais: Ressalta-se a importância de se realizar mais produções científicas sobre essa temática, promovendo uma melhoria de assistência a essas mulheres, de forma mais humanizada.

Palavras-chave: Aborto legal, Clínica, Medicina.

\begin{abstract}
Objective: Given this, it is of great importance that professionals who perform this procedure have clinical and legal knowledge on the subject. Therefore, this review aimed to carry out an analytical research on the clinical and legal aspects of legal abortion in the context of medicine. Methods: This is an analytical, documentary study, of the integrative literature review type, the search was carried out in the SCIELO, LILACS, BDENF and PUBMED databases. Results: 10 studies were selected, which addressed the clinical and legal perspectives of legal abortion in Brazil. Studies have shown that this theme is still surrounded by stigmas, and that many professionals do not have sufficient knowledge of the legislation. In addition, another issue raised in the studies is that many women who suffer rape and become pregnant are discredited by professionals, needing to present a document that proves this fact. Final considerations: Thus, it emphasizes the importance of carrying out more scientific productions on this theme, promoting an improvement in care for these women, in a more humanized way.
\end{abstract}

Keywords: Legal abortion, Clinic, Medicine.

\section{RESUMEN}

Objetivo: Ante esto, es de gran importancia que los profesionales que realizan este procedimiento tengan conocimientos clínicos y legales sobre el tema. Por lo tanto, esta revisión tuvo como objetivo realizar una investigación analítica sobre los aspectos clínicos y legales del aborto legal en el contexto de la medicina.

1 Universidade Estadual do Pará (UEPA), Belém - PA. *E-mail: robertojr4763@gmail.com 
Métodos: Se trata de un estudio analítico, documental, del tipo revisión integradora de la literatura, la búsqueda se realizó en las bases de datos SCIELO, LILACS, BDENF y PUBMED. Resultados: Se seleccionaron 10 estudios, que abordaron las perspectivas clínicas y legales del aborto legal en Brasil. Los estudios han demostrado que este tema todavía está rodeado de estigmas y que muchos profesionales no tienen suficiente conocimiento de la legislación. Además, otra cuestión planteada en los estudios es que muchas mujeres que sufren violación y quedan embarazadas son desacreditadas por los profesionales, debiendo presentar un documento que acredite este hecho. Consideraciones finales: De esta manera, se enfatiza la importancia de realizar más producciones científicas sobre este tema, promoviendo una mejora en la atención a estas mujeres, de una manera más humanizada.

Palabras clave: Aborto legal, Clínica, Medicina.

\section{INTRODUÇÃO}

O aborto é considerado um grande problema de saúde pública, uma vez que o mesmo têm uma ampla incidência no Brasil, e também é uma temática que é permeada de tabus, bem como discussões, que são levantadas pela defesa da descriminação dessa prática, e também para a sua criminalização. Essa temática é discutida no campo da ciência que chama-se "bioética das situações persistentes", pois essa temática do aborto desperta uma série de reflexões que está relacionada à autonomia da mulher, no que diz respeito ao que fazer com seu corpo, que é estudado tanto na visão de profissionais de saúde pública e também suas implicações no contexto ético político (MENDES RWM, et al., 2020).

No estudo de Fróes NMF e Batista CB (2021), os autores abordam sobre a diferença do termo "abortamento" e do termo "aborto", que quando abordado na literatura técnica são vistas como palavras sinônima, entretanto, os autores ressaltam que, o termo "abortamento" é relacionamento a interrupção da gravidez até a $20^{\mathrm{a}}$ ou $22^{\mathrm{a}}$ semana com produto de peso inferior a $500 \mathrm{~g}$, enquanto que o termo "aborto" é o desfecho do abortamento.

Essa prática de abortamento apresenta grande impacto na saúde de mulheres brasileira, sendo uma das principais causas de mortalidade materna. E vale ressaltar que em alguns países, assim como no Brasil, a prática de abortamento é ilegal, considerada um crime na maioria das situações, sendo ainda um ato cruel com mulheres que estão em camadas sociais mais baixas, sendo consideras mais vulneráveis (CARDOSO BB, et al., 2020).

Diante disso, Cardoso BB, et al. (2020) ressalta que devido ao fato dessa prática ser criminalizada, culmina por favorecer a realização da mesma de forma ilegal, sem uma estrutura adequada para tal prática, o que resulta em uma assistência de má qualidade, e devido a esse fato, há um número elevado de abortos induzidos no Brasil.

Dados da Pesquisa Nacional de Aborto (PNA) (2016) afirmaram que entre os anos de 2010 a 2014 foram realizados cerca de 25,1 milhões de abortos inseguros em todo o mundo, sendo que 24,3 milhões desses abortos foram notificados em países em desenvolvimento. No Brasil, os dados mostraram que quase uma em cada cinco mulheres brasileiras já realizaram aborto aos quarenta anos (DINIZ D, et al., 2016).

Nos países em que a prática de abortamento é ilegal, como no caso do Brasil, o aborto clandestino é realizado por mulheres de diversas classes sociais, porém as mulheres em situação de vulnerabilidade social e socioeconômica são as que têm mais consequências graves. Essas consequências são associadas as condições precárias que é realizado o abortamento, e sobre essa prática, a Organização Mundial da Saúde (OMS) define essa prática como abortamento inseguro (PACAGNELLA RC, et al., 2020).

Sobre a legislação do aborto no Brasil, essa temática é contemplada no Artigo 128 do Código Penal de 1940, e coloca como exceção para a realização da prática somente aquela gravidez resultante de estupro, que pode ser realizado sob autorização da gestante ou de um representante legal, caso seja uma mulher incapaz, e ainda está previsto em lei o abortamento em casos de risco à gestante. Nos casos de alguma 
anomalia fetal que seja incompatível com a vida, mesmo que não esteja na legislação, a interrupção da gravidez pode ser solicitada, caso haja interesse da gestante e somente diante de uma autorização judicial (BENUTE GRG, et al., 2012).

Com o objetivo de diminuir os casos de abortamento ilegal, em 1999, o Ministério da Saúde criou um documento que regulamenta dos serviços de aborto legal no Brasil, que é a norma técnica "Prevenção e Tratamento dos Agravos Resultantes da Violência Sexual contra Mulheres e Adolescentes. Essa norma foi o primeiro texto que abordou sobre a lacuna deixada pelo Código Penal, que é sobre a conduta para estabelecer a verdade no caso da exceção punitiva para o aborto. Após diversas discussões relacionadas a controvérsia moral foi votado pela revisão e ampliação do documento, que ocorreu em 2005 , tendo a sua última revisão em 2012 (DINIZ D, et al., 2014).

Porém, mesmo com esse avanço na implementação de uma política pública voltada para as mulheres vítimas de violência sexual, a realização do processo de abortamento ainda não é permitida para mulheres brasileiras. E quanto ao aborto legal no Brasil, no ano de 2005, o número de hospitais cadastrados com equipes para a realização do abortamento nos casos previstos na lei, equivalia 56 hospitais, porém, apenas 37 estavam capacitados para realizar tal procedimento, e desses 37 hospitais, 5 nunca haviam realizado 0 abortamento legal. Outro fator também é que, seis estados do Brasil, ainda não dispunham de um serviço organizado, sendo os atendimentos realizados na maioria das vezes na região Sudeste, que acabava sendo sobrecarregado, recebendo mulheres de várias regiões (GIULGLIANI C, et al., 2019).

Sendo assim, o objetivo do presente estudo foi realizar uma pesquisa analítica dos aspectos clínicos e jurídicos do aborto legal no contexto da medicina.

\section{MÉTODOS}

A presente pesquisa trata-se de um estudo analítico, documental, do tipo revisão integrativa. Segundo Alemida PRC, et al. (2015), a revisão integrativa é um tipo de estudo que agrega diversos estudos e resultados encontrados, sob a ótica de metodologias distintas, fazendo com que os revisores possam organizar esses resultados de forma sistematizada, através de um método rigoroso, nem influenciar na qualidade dos estudos.

Os estudos incluídos obedeceram satisfatoriamente a pergunta da pesquisa: "Qual a percepção clínica e jurídica do aborto legal no contexto da medicina?". As características dos estudos foram detalhadas considerando a identificação do autor, ano de publicação e local do estudo, bem como tipo de abordagem, objetivos e principais resultados, para estudos no idioma português.

Sobre o estudo descritvo, Prodonav CC e Freitas EC (2013), afirmam que é o tipo de estudo que tem por objetivo elucidar sobre características de alguma população ou de um fenômeno, ou ainda o estabelecimento de uma relação entre variáveis. Esse tipo de estudo é realizado com base é uma técnica especializada e sistematizada.

Nesse tipo de estudo a coleta de dados pode ser realizada através de algumas técnicas, que podem ser através do uso de instrumentos validados, como questionários prontos ou adaptados, além também dessa coleta de dados, quando for um estudo do tipo revisão, pode ser feita através de uma observação sistemática.

Esse tipo de pesquisa utiliza técnicas de observação, realiza os registros, analisa os dados encontrados e organiza, sem alterar os resultados obtidos, ou seja, sem a interferência do pesquisador. O principal objetivo do estudo descritivo é descobrir qual a frequência que um fenômeno ocorre, bem como sua natureza, as suas particularidades, a causa daquele evento e os fatores envolvidos.

E como para esse tipo de estudo é utilizado técnicas específicas para a coleta de dados, na presente revisão, foi utilizado um instrumento validado para a seleção dos estudos, portanto, o presente estudo de revisão está organizado de acordo com as orientações recomendação Preferred Reporting Items for Systematic Reviews and Meta-Analyses (PRISMA), esse método consiste na elaboração de um fluxograma, que é dividido em quatro etapas (identificação, triagem, elegibilidade, inclusão) (Figura 1), essa técnica é 
composta por um checklist que contem 27 itens e o fluxograma, essa técnica se faz relevantes por auxilia para uma melhor escrita de revisões, assim como na crítica de estudos já publicados (GALVÃO TF, et al., 2015).

Figura 1 - Fluxograma da seleção dos artigos, segundo o método de PRISMA.

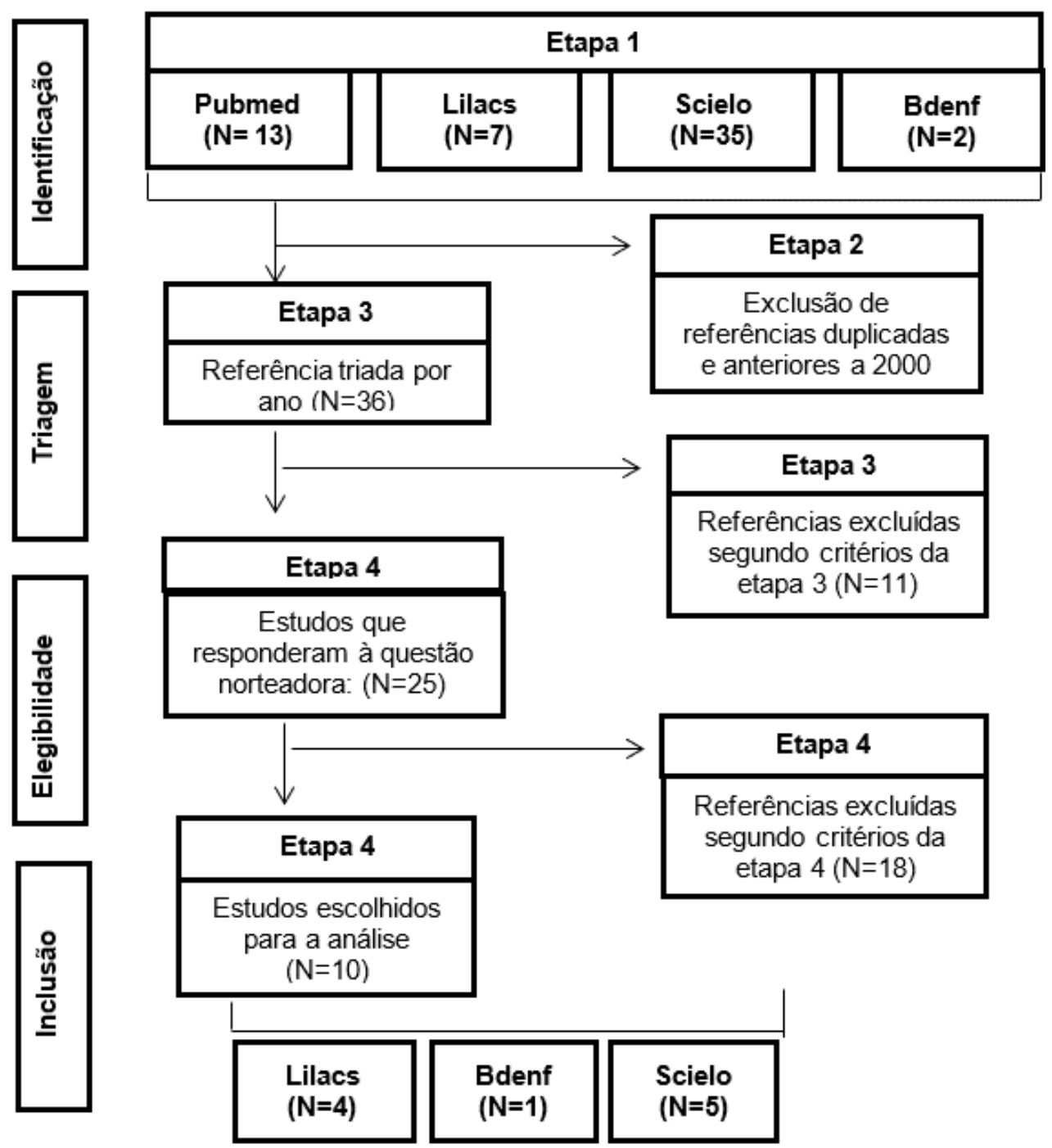

Fonte: Júnior RSA, et al., 2021.

As etapas da pesquisa se inciaram com uma busca nas bases de dados Library of Medicine(PUBMED), Brasil Scientific Electronic Library Online (SCIELO), Literatura Latino-americana e do Caribe em Ciências da Saúde (LILACS) e Base de dados da Enfermagem(BDENF), em que foram utilizado os seguintes descritores no Descritores em Ciências da Saúde(DECS): "Aborto OR Abortamento" AND "Aborto Legal" AND "Medicina" AND "Aspectos clínicos" AND "Legislação" que deveria estar presente no corpo do texto, sem restrição de ano.

Após essa etapa, foi realizada a leitura de todos os títulos e aplicação dos critérios de inclusão e exclusão. Em seguida, foi feita a leitura dos resumos na íntegra, para analisar se os estudos se enquadravam na proposta da pesquisa. Os critérios aplicados foram: artigos disponibilizados na íntegra, disponíveis nos idiomas português e inglês, publicados entre os anos de 2010 a 2021 e que abordassem sobre os aspectos jurídicos do aborto legal no cenário da medicina. Os critérios de exclusão foram: artigos incompletos, cartas ao editor, debates, resenhas, resumos ou artigos publicados em anais de eventos, indisponíveis na íntegra e duplicados. E na última etapa foi feita a categorização dos estudos selecionados. 


\section{RESULTADOS}

\section{Caracterização dos estudos}

Foram selecionados 10 estudos, que abordam sobre perspectivas clínicas e jurídicas do aborto legal no Brasil, dentre esses estudos, cinco foram encontrados na base de dados SCIELO, quatro a LILACS e um na BDENF, quanto ao tipo de periódico, a maioria dos estudos foram publicados em revistas de saúde pública ou saúde coletiva, seguida de revistas de bioética e revistas voltadas para ginecologia e obstetrícia.

Quanto ao ano de publicação, 2020 foi o que teve mais estudos publicados, totalizando três, seguido do ano de 2012, com dois estudos, e sobre o idioma todos estavam em português, ressalta-se que idioma ainda é um fator limitador, uma vez que a maioria dos estudos em inglês não estão disponíveis na gratuitamente, e sobre o tipo de estudo, houve maior prevalência de estudos transversais, do tipo quantitativo ou qualitativo (Quadro 1).

Quadro 1 - Caracterização dos estudos selecionados quanto a revista, base de dados, ano, idioma e tipo de estudo.

\begin{tabular}{|c|l|l|l|l|}
\hline REVISTA & $\begin{array}{c}\text { BASE DE } \\
\text { DADOS }\end{array}$ & ANO & IDIOMA & $\begin{array}{c}\text { TIPO DE } \\
\text { ESTUDO }\end{array}$ \\
\hline Revista Bioética & SCIELO & 2021 & Português & $\begin{array}{c}\text { Transversal } \\
\text { Analítico }\end{array}$ \\
\hline $\begin{array}{c}\text { Interface, comunicação, saúde e } \\
\text { educação }\end{array}$ & SCIELO & 2019 & Português & Qualitativo \\
\hline $\begin{array}{c}\text { Caderno de Saúde Pública } \\
\text { Revista Bioética }\end{array}$ & SCIELO & 2020 & Português & $\begin{array}{c}\text { Transversal } \\
\text { Quantitativo }\end{array}$ \\
\hline Ciência e Saúde Coletiva & SCIELO & 2012 & Português & $\begin{array}{c}\text { Transversal } \\
\text { Qualitativo }\end{array}$ \\
\hline $\begin{array}{c}\text { Revista Brasileira de } \\
\text { Ginecologia e obstetrícia }\end{array}$ & LILACS & 2012 & Português & Portutivo \\
\hline Revista de Saúde Pública & LILACS & 2011 & Português & Revisão bibliográfica \\
\hline Ciência e Saúde Coletiva & LILACS & 2016 & Português & Quantitativo \\
\hline Caderno de Saúde Pública & LILACS & 2020 & Português & Revisão Sistemática \\
\hline Revista FEMINA & BDENF & 2020 & Português & $\begin{array}{c}\text { Estudo de campo, } \\
\text { quantitativo }\end{array}$ \\
\hline
\end{tabular}

Fonte: Júnior RSA, et al., 2021.

Também foi feito um quadro síntese dos estudos encontrados, que aborda sobre os autores, o título do estudo, o objetivo principal e as principais conclusões encontradas pelos autores (Quadro 2). 
Quadro 2 - Descrição dos estudos selecionados de acordo com a variável autor, título, objetivo e conclusões dos estudos.

\begin{tabular}{|c|c|c|c|}
\hline AUTOR & TíTULO & OBJETIVO & CONCLUSÕES \\
\hline $\begin{array}{l}\text { Fróes NMF, et al., (2021) } \\
\qquad \text { (A1) }\end{array}$ & $\begin{array}{l}\text { Conhecimento e percepção de } \\
\text { estudantes de medicina sobre } \\
\text { abortamento legal }\end{array}$ & $\begin{array}{l}\text { Avaliar o conhecimento de estudantes da } \\
\text { Faculdade de Medicina da Bahia da } \\
\text { Universidade Federal da Bahia sobre as leis } \\
\text { que permitem o aborto no Brasil, bem como a } \\
\text { percepção desses estudantes sobre o tema }\end{array}$ & $\begin{array}{l}\text { Os resultados demonstram a necessidade de } \\
\text { fortalecer a abordagem do tema durante a graduação, } \\
\text { de modo multidisciplinar e transversal. Vale ressaltar, } \\
\text { por fim, que se observou entre os participantes } \\
\text { inclinação favorável à descriminalização do aborto. }\end{array}$ \\
\hline $\begin{array}{l}\text { Pacagnella RC, et al., } \\
\qquad \begin{array}{l}(2020) \\
\text { (A3) }\end{array}\end{array}$ & $\begin{array}{l}\text { Conhecimento de médicos } \\
\text { residentes em Ginecologia e } \\
\text { Obstetrícia sobre o aborto medica- } \\
\text { mentoso }\end{array}$ & $\begin{array}{l}\text { Identificar o grau de conhecimento dos } \\
\text { médicos residentes em Ginecologia e } \\
\text { Obstetrícia sobre aborto medicamentoso }\end{array}$ & $\begin{array}{l}\text { Entre os médicos brasileiros residentes em } \\
\text { Ginecologia e Obstetrícia, o conhecimento sobre o } \\
\text { aborto medicamentoso é muito reduzido e constitui um } \\
\text { obstáculo para o bom atendimento dos casos de } \\
\text { interrupção legal da gestação }\end{array}$ \\
\hline Diniz D, et al., (2014) & $\begin{array}{l}\text { A verdade do estupro nos serviços } \\
\text { de aborto legal no Brasil }\end{array}$ & $\begin{array}{c}\text { Analisa como se constrói a verdade do estupro } \\
\text { para que a mulher que se apresenta como } \\
\text { vítima tenha acesso ao aborto legal no Brasil }\end{array}$ & $\begin{array}{c}\text { A verdade do estupro para o aborto legal não se } \\
\text { resume à narrativa íntima e com presunção de } \\
\text { veracidade, mas é uma construção moral e discursiva } \\
\text { produzida pela submissão da mulher aos regimes } \\
\text { periciais dos serviços. }\end{array}$ \\
\hline Zordo S, (2012) & $\begin{array}{c}\text { Representações e experiências } \\
\text { sobre aborto legal e ilegal dos } \\
\text { ginecologistas-obstetras trabalhan- } \\
\text { do em dois hospitais maternidade } \\
\text { de Salvador da Bahia }\end{array}$ & $\begin{array}{l}\text { Investigar a experiência e as representações } \\
\text { do aborto legal, analisadas em contraste com } \\
\text { as representações do aborto ilegal, dos } \\
\text { profissionais de saúde, em particular dos } \\
\text { ginecologistas-obstetras. }\end{array}$ & $\begin{array}{l}\text { Os fatores principais associados à atitudes liberais } \\
\text { foram: a idade - abaixo de 30/acima de } 45 \text { anos - a } \\
\text { experiência com altas taxas de mortalidade materna } \\
\text { devidas ao aborto e a experiência com o aborto legal }\end{array}$ \\
\hline
\end{tabular}




\begin{tabular}{|c|c|c|c|}
\hline AUTOR & TÍTULO & OBJETIVO & CONCLUSÕES \\
\hline $\begin{array}{l}\text { Benute GRG, et al., } \\
\qquad \begin{array}{l}\text { (2012) } \\
\text { (A6) }\end{array}\end{array}$ & $\begin{array}{l}\text { Influência da percepção dos } \\
\text { profissionais quanto ao aborto } \\
\text { provocado na atenção à saúde da } \\
\text { mulher }\end{array}$ & $\begin{array}{l}\text { Identificar o conhecimento e a percepção dos } \\
\text { profissionais da saúde em relação à legislação } \\
\text { brasileira sobre o aborto provocado. }\end{array}$ & $\begin{array}{c}\text { Evidenciou-se o desconhecimento dos profissionais de } \\
\text { saúde com relação à legislação brasileira, em menor } \\
\text { proporção entre obstetras e em maior proporção entre } \\
\text { os profissionais da área de enfermagem. Foram } \\
\text { constatadas atitudes de discriminação, julgamento e } \\
\text { preconceito na assistência prestada às mulheres que } \\
\text { provocam o aborto. }\end{array}$ \\
\hline $\begin{array}{l}\text { Diniz D, (2011) } \\
\qquad(A 7)\end{array}$ & $\begin{array}{l}\text { Objeção de consciência e aborto: } \\
\text { direitos e deveres dos médicos na } \\
\text { saúde pública }\end{array}$ & $\begin{array}{l}\text { O artigo discute a objeção de consciência por } \\
\text { médicos, tendo por situação concreta os } \\
\text { serviços de aborto legal no Brasil }\end{array}$ & $\begin{array}{c}\text { A partir dessas duas teses, propõe uma terceira, a da } \\
\text { justificação, como forma de orientar o exercício do } \\
\text { direito à objeção de consciência entre médicos nesses } \\
\text { serviços }\end{array}$ \\
\hline $\begin{array}{l}\text { Madeiro AP e Diniz D, } \\
\qquad \begin{array}{l}(2016) \\
\text { (A8) }\end{array}\end{array}$ & $\begin{array}{c}\text { Serviços de aborto legal no Brasil - } \\
\text { um estudo nacional }\end{array}$ & $\begin{array}{c}\text { Descreve os resultados de umestudo com } \\
\text { métodos mistos nos serviços de aborto legal } \\
\text { no país }\end{array}$ & $\begin{array}{l}\text { Os dados mostram que ainda há distanciamento entre } \\
\text { a previsão legal e a realidade dos serviços. A } \\
\text { implementação de novos serviços e o fortalecimento } \\
\text { dos existentes são ações necessárias. }\end{array}$ \\
\hline $\begin{array}{l}\text { Mendes RWM, et al., } \\
\qquad(2020) \\
\text { (A9) }\end{array}$ & $\begin{array}{c}\text { Objeção de cons-ciência na } \\
\text { dinâmica do atendimento ao aborto } \\
\text { legal em Minas Gerais }\end{array}$ & $\begin{array}{l}\text { Verificar a existência da objeção de } \\
\text { consciência na atenção integral à saúde das } \\
\text { vítimas de violência sexual, bem como } \\
\text { conhecer a estrutura de atendimento das } \\
\text { instituições credenciadas na rede de atenção } \\
\text { à vítima de violência sexual no Estado de } \\
\text { Minas Gerais. }\end{array}$ & $\begin{array}{c}\text { O sistema de assistência no Estado não está } \\
\text { preparado para o atendimento integral às vítimas de } \\
\text { violência sexual, principalmente no quesito resolução } \\
\text { do aborto legal, sendo a objeção de consciência o } \\
\text { maior obstáculo. }\end{array}$ \\
\hline $\begin{array}{l}\text { Fonseca SC, et al., } \\
\qquad \begin{array}{c}(2020) \\
(\text { A10) }\end{array}\end{array}$ & $\begin{array}{l}\text { Aborto legal no Brasil: revisão } \\
\text { sistemática da produção científica, } \\
2008-2018\end{array}$ & $\begin{array}{l}\text { Atualizar o conhecimento sobre o aborto legal, } \\
\text { quanto ao perfil dos serviços, das mulheres } \\
\text { atendidas, conhecimento de estudantes e } \\
\text { médicos, situação de anencefalia e } \\
\text { malformações graves }\end{array}$ & $\begin{array}{c}\text { O conhecimento sobre o aborto legal ainda é escasso, } \\
\text { a demanda do procedimento é reprimida e a formação } \\
\text { médica é deficiente no tema. }\end{array}$ \\
\hline
\end{tabular}

Fonte: Júnior RSA, et al., 2021. 


\section{DISCUSSÃO}

Autores afirmam que há uma estimativa, de que, a cada ano, cerca de 230 mil mulheres são atendidas no Sistema Único de Saúde (SUS) em consequência de algum aborto inseguro (FLEURY TE e MENEGHEL SN, 2015). E também, outro fator importante é que dentre as causas de óbito materno no Brasil, notificados nos últimos anos, o aborto é tido como uma dessas principais causas (SILVA BGC, et al., 2016). Portanto, o aborto é considerado um grave problema de saúde, sendo uma questão que precisa ser debatida. Estudiosos importantes afirmam que, mesmo com os progressos que ocorreram no Brasil nos últimos anos, a mortalidade materna devido ao aborto inseguro ainda continua sendo um desafio que precisa estudado (VICTORIA CG, et al., 2011).

A temática sobre o aborto é bastante complexa e antiga, uma vez que existem controvérsias que variam de intensidade sobre se e quando o aborto pode ser realizado, bem como quais as situações que justificam essa prática, ou ainda o entendimento de quando se inicia a vida (GIUGLIANI C, et al., 2018).

A prática de abortamento pode ser caracterizada como a interrupção da gestação ou a expulsão do feto, antes que seja viável, que pode ser até 22 semanas de gestação, ou ainda com o produto da concepção com um peso menos que 500 gramas ou com menos de 16 centímetros (MACHIN R, et al., 2019).

Atualmente, no Brasil, o aborto é criminalizado, sendo que de acordo com a lei relacionada ao abortamento desde 1940, é permitido em casos de gravidez resultante de estupro e risco de vida da gestante. O abortamento previsto por lei, ou aborto legal, considera apenas essas suas exceções, de acordo com o previsto no Artigo 128 do código penal (CARDOSO BB, et al., 2020). E desde 2012, casos de fetos que apresentem anencefalia (MACHIN R, et al., 2019).

Nessa época, o Conselho Federal de Medicina, publicou uma resolução, abordando sobre o diagnóstico da anencefalia para os casos que requerem antecipação terapêutica do parto (FROES NMF e BATISTA CB, 2021). Porém, a partir do ano de 1980, mulheres têm buscado na justiça brasileira o direito de abortar nessas situações, sendo estas, autorizadas a realizar o procedimento na maioria das vezes (CONSELHO FEDERAL DE MEDICINA, 2012).

O aborto seguro, que é praticado legalmente, seguido os casos previstos na lei, deve ser realizado em serviço de saúde estruturado, com equipe multiprofissional capacitada e que ofereça a mulher toda a atenção necessária (FROES NMF e BATISTA CB, 2021). Segundo o Código Penal brasileiro, no artigo 124, crime contra a vida "provocar aborto em si mesma ou consentir que outrem Ihe provoque", elencando as penalidades até o artigo 127. E quando o aborto é a única opção para salvar a vida da mulher, ou quando a gestação é decorrente de estupro, desde que a mulher deseje se submeter ao procedimento e seja realizado por um médico, o artigo 128 isenta de pena (MINISTÉRIO DA SAÚDE, 1940).

De acordo com Banute GRG, et al. (2012) o aborto é uma temática que está associada a vivência da mulher, incluído nas políticas pública e de saúde nos programa de atenção à saúde da mulher. E essa temática também está incluída na formação acadêmica de profissionais da saúde, especialmente da medicina e da enfermagem.

E mesmo fazendo parte da preparação para a formação profissional, essa técnica ainda é influenciada por concepções morais, sociais e religiosas, fazendo com que haja uma resistência para a aceitação do tema, e como consequência, há uma assistência ineficaz, que muitas vezes é norteada pela concepção de que o aborto é um crime, sem analisar os direitos sexuais e reprodutivos da mulher, ou ainda as questões sociais que permeiam essa prática, o que acaba por influenciar a realização do aborto de forma clandestina (BANUTE GRG, et al., 2012).

Segundo Madeiro AP e Diniz D (2016), mesmo com os avanços obtidos com a instalação de serviços em todas as regiões do país, tais como a necessidade de autorização judicial para a realização do aborto previsto em lei, outra dificuldade é que muitos ginecologistas e obstetras solicitam Boletim de Ocorrência (BO) ou outro tipo de documento, como laudo do Instituto Médico Legal (IML). E outro fator que também dificulta, em casos de estupro, é que muitas vezes a mulher é desacreditada, sendo que apenas o seu relato não é suficiente 
para garantir o direito ao abortamento legal, necessitando de provas concretas, como laudos e/ou resultados de exames que comprovem a violência. Apenas o relato feito pela vítima não é válido para a mesma interromper a gravidez.

Analisando que o tema aborto ainda é permeado por estigmas no Brasil, espera-se que haja uma dificuldade de abordar essa temática, principalmente dentro das instituições de ensino, mesmo com um aumento significativo de estudantes de medicina que só vêm aumentando. Portanto se faz necessário que haja um esclarecimento sobre os aspectos clínicos e jurídicos que permeiam essa temática, ressalta-se que o esclarecimento sobre questões ética, legais e clínicas irá corroborar para a redução dos agravos e prevenção de abortos inseguros (GIUGLIANI C, et al., 2019).

E outra dificuldade também encontrada para a estruturação do aborto legal, é a identificação de profissionais de saúde com a disponibilidade para assistir as mulheres no abortamento legal. Seja pelo estigma se serem vistos como profissionais "aborteiros", e o receio de serem processados, ou ainda pela objeção de consciência, que pode ser devido a uma conduta moral ou religiosa (MADEIRO AP e DINIZ D, 2016).

Dessa forma, o direito a objeção de consciência, que pode ser solicitado por médicos e estudantes, muitas vezes é recorrido devido a preceitos religiosos, que são como uma válvula de escape. E nesse contexto, esse direito é requerido para que os profissionais possam se isentar de realizar uma assistência, e que em muitos casos não é por princípios morais ou religiosos, mas por receio de sofrerem algum tipo de retalhação ou preconceito, uma vez que esse direito é mais usado em casos de violência sexual (FONSECA SC, et al., 2020).

Porém, esse direito não é concreto quando prejudica a saúde de pessoas. Portanto, o direito à objeção de consciência dispõe de limites, sendo que os profissionais não podem dispor desse direito em situações que são caracterizadas como urgência, tais situações como: risco óbito da gestante; abortamento permitido de acordo com a lei vigente, ausência de um profissional que realize; probabilidade de a mulher sofrer algum agravo ou consequência a sua saúde em razão da omissão do profissional; e complicações decorrentes de abortamento inseguro (MENDES RWM, et al., 2020).

E quando se trata do aborto em serviço de saúde, o dilema não é somente entre o profissional e a gestante. A objeção de consciência pode ser considerada como um tipo de conflito de responsabilidade, uma vez que envolve direitos individuais e questões pessoais do próprio profissional, dentro os direitos individuais que podem ser violados, destaca-se o direito a intimidade, a liberdade de consciência, bem como a autonomia do indivíduo, e também ainda existe os direitos constitucionais (DINIS D, 2011).

È importante frisar que, mesmo que o Código de Ética Médica, por sua vez, coloca como princípios essenciais para o desenvolvimento da profissão o seguinte: atuar com o propósito de melhorar à saúde do ser humano com o máximo de dedicação e o máximo de sua capacidade profissional, buscando sempre se embasar na literatura científica, visando o benefício para o seu paciente. Quanto as responsabilidades profissionais, é proibido ao profissional médico permitir que suas concepções pessoais, sociais e morais interferiram na sua tomada de decisão adequada, dificultando as melhores estratégias de prevenção, diagnóstico ou tratamento que sejam eficazes e reconhecidos pela literatura científica (CONSELHO FEDERAL DE MEDICINA, 2010).

Dentro do campo da bioética, o aborto é uma situação persistente, parecendo ser um assunto muito discutido e consolidado, porém, a realizado assistencial é um descaso muito grande no atendimento às mulheres, principalmente vítimas de violência sexual. Por essas razões, a bioética não pode ficar estagnada apenas em reflexões, convicções e discursos teóricos e retóricos, enquanto mulheres estão sendo violentadas não só pela situação do aborto legal, mas também pela falta de assistência adequada por equipes multiprofissionais e interdisciplinares (MENDES RWM, et al., 2020).

Diante disso, Giugliani C, et al. (2019) ainda elenca que é frequente no discurso de profissionais da saúde sobre os aspectos éticos que envolvem essa temática, questões essas que acabam por dificultar o acolhimento e cuidado das mulheres que têm o desejo de realizar o aborto. Porém, quando analisado a 
questão embasada no código de ética profissional, esse tipo de conduta é ilegal, ocorrendo quando há a omissão de informações importantes e embasadas na literatura científica que pode corroborar para salvar a vida de uma mulher que está decidida a abortar.

Portanto, é denominado como quebra de sigilo, quando um profissional da medicina denuncia às autoridades policiais mulheres que provocam aborto, mesmo essa prática sendo considerada ilegal no Brasil. Outro fator também ainda evidenciado é que muitas mulheres ainda são desacreditadas quando chegam ao serviço procurando informações sobre aborto, conduta essa que é mais frequente em mulheres que são vítimas de violência sexual, uma vez que a principal conduta adotada pelo profissional é a exigência de um documento que comprove os relatos da vítima (GIUGLIANI C, et al., 2019).

\section{CONSIDERAÇÕES FINAIS}

Dessa forma, o presente estudo vem enfatizar que, para ter uma assistência humanizada, integral e universalizada para essa mulher no âmbito do SUS, é muito importante que os profissionais tenham os conhecimentos técnicos e jurídicos acerca do processo de abortamento, para assim evitar julgamentos prévios. E por fim, quanto as limitações do estudo, o mesmo se diz respeito a estudos de campo sobre a temática, uma vez que muitos estudos são de revisão de literatura, que podem haver viés. Portanto, ressaltase que a produção de pesquisas científicas sobre a temática pode colaborar para criação e melhoria de políticas públicas acerca dos direitos sexuais e reprodutivos das mulheres. Portanto, o aborto continua sendo uma causa muito importante a ser debatida, entretanto essa temática ainda permeada por estigmas e tabus, mesmo quando se trata de aborto legal. $E$ apesar de serem capacitados para realizar tal procedimento, ainda há dificuldade de se identificar profissionais que o queiram fazer, devido a questões religiosas ou morais, e muitos ainda optam pela objeção de consciência.

\section{REFERÊNCIAS}

1. ALMEIDA PRC, et al. Condição de saúde de mulheres privadas de liberdade: uma revisão integrativa. Revista Brasileira de Ciências da Saúde, 2015; 19(1): 73-80.

2. BENUTE GRG, et al. Influência da percepção dos profissionais quanto ao aborto provocado na atenção à saúde da mulher. Revista Brasileira de Ginecologia e Obstetrícia, 2012; 34:69-73.

3. CARDOSO BB, et al. Aborto no Brasil: o que dizem os dados oficiais? Cad. Saúde Pública, Rio de Janeiro, 2020; $36(1)$.

4. CONSELho FederAL DE MEDiCINA. Código de Ética Médica. Resolução CFM no 1.931, de 17 de setembro de 2009. Brasília: Conselho Federal de Medicina; 2010. Disponível em: https://portal.cfm.org.br/images/stories/biblioteca/codigo\%20de\%20etica\%20medica.pdf. Acessado em: 09 de novembro de 2021.

5. DINIZ D. Objeção de consciência e aborto: direitos e deveres dos médicos na saúde pública. Revista de Saúde Pública, 2011; 45: 981-985.

6. DINIZ D, et al. A verdade do estupro nos serviços de aborto legal no Brasil. Revista Bioética, 2014; $22: 291-298$.

7. DINIZ D, et al. Pesquisa nacional de aborto 2016. Ciência \& Saúde Coletiva, 2016; 22: 653-660.

8. FLEURY TE, MEGEGHEL SN. Dicionário Feminino da Infâmia: acolhimento e diagnóstico de mulheres em situação de violência. $1^{\circ}$ ed. Rio de Janeiro: FIOCRUZ; 2015; 1-422p.

9. FONSECA SC, et al. Aborto legal no Brasil: revisão sistemática da produção científica, 2008-2018. Cadernos de Saúde Pública, 2020; 36: e00189718.

10. FRÓES NMF, BATISTA CB. Conhecimento e percepção de estudantes de medicina sobre abortamento legal. Revista Bioética, 2021; 29: 194-207.

11. GALVÃO TF, et al. Principais itens para relatar Revisões sistemáticas e Meta-análises: A recomendação PRISMA. Epidemiologia e Serviços de Saúde, 2015; 24: 335-342.

12. GIUGLIANI C, et al. O direito ao aborto no Brasil e a implicação da Atenção Primária à Saúde. Rev Bras Med Fam Comunidade, Rio de Janeiro, 2019; 41: 179.

13. MACHIN R, et al. Formação médica e assistência aos processos de abortamento: a perspectiva de residentes de duas universidades públicas em São Paulo, Brasil. Interface-Comunicação, Saúde, Educação, 2019; 23: 1-15.

14. MADEIRO AP, DINIZ D. Serviços de aborto legal no Brasil-um estudo nacional. Ciência \& Saúde Coletiva, 2016; 21 : 563-572. 
15. MENDES RWM, et al. Objeção de consciência na dinâmica do atendimento ao aborto legal em Minas Gerais. Femina, 2020; 48: 646-653.

16. MINISTÉRIO DA SAÚDE. Lei $n^{\circ} 2.848$ de 7 de setembro 1940.Disponível em: http://www.planalto.gov.br/ccivil_03/decreto-lei/del2848.htm. Acessado em 21 de outubro de 2021.

17. PACAGNELLA RC, et al. Conhecimento de médicos residentes em Ginecologia e Obstetrícia sobre o aborto medicamentoso. Cadernos de Saúde Pública, 2020; 36:e00187918.

18. PRODANOV CC, FREITA EC. Metodologia do Trabalho Científico. Métodos e Técnicas da Pesquisa e do Trabalho Acadêmico. $2^{\mathrm{a}}$ ed. Novo Hamburgo: Editora Feevale, 2013: 1-277p.

19. SILVA BGC, et al. Mortalidade materna no Brasil no período de 2001 a 2012: tendência temporal e diferenças regionais. Rev Bras Epidemiol. 2016; 19: 484-93.

20. VICTORIA CG, et al. Saúde de mães e crianças no Brasil: progressos e desafios. Lancet. 2011; 32-46.

21. ZORDO S. Representações e experiências sobre aborto legal e ilegal dos ginecologistas-obstetras trabalhando em dois hospitais maternidade de Salvador da Bahia. Ciência \& Saúde Coletiva, 2012; 17: 1745-1754. 